Article publié par le Laboratoire de Construction en Béton de l'EPFL

\begin{tabular}{|l|l|}
\hline Title: & $\begin{array}{l}\text { Behaviour of nodal regions of reinforced concrete frames subjected to opening } \\
\text { moments and proposals for their reinforcement }\end{array}$ \\
\hline Authors: & Campana S., Fernández Ruiz M., Muttoni A. \\
\hline Published in: & Engineering Structures http:/www.elsevier.com/locate/engstruct \\
\hline DOI & $10.1016 /$ j.engstruct.2013.01.029 \\
\hline $\begin{array}{l}\text { Volume: } \\
\text { Pages: }\end{array}$ & $\begin{array}{l}\text { Vol. } 51 \\
\text { pp. } 200-210\end{array}$ \\
\hline Year of publication: & 2013 \\
\hline Type of publication: & Peer reviewed journal article \\
\hline
\end{tabular}

\begin{tabular}{|l|l|}
\hline Please quote as: & $\begin{array}{l}\text { Campana S., Fernández Ruiz M., Muttoni A., Behaviour of nodal regions of } \\
\text { reinforced concrete frames subjected to opening moments and proposals for their } \\
\text { reinforcement, Engineering Structures, Vol. 51, 2013, pp. 200-210. }\end{array}$
\end{tabular}




\title{
Behaviour of nodal regions of reinforced concrete frames subjected to opening moments and proposals for their reinforcement
}

\author{
Stefano Campana, Miguel Fernández Ruiz*, Aurelio Muttoni \\ School of Architecture, Civil and Environmental Engineering (ENAC), Ecole Polytechnique Fédérale de Lausanne, Switzerland
}

\section{A R T I C L E I N F O}

\section{Article history:}

Received 29 June 2012

Revised 22 January 2013

Accepted 28 January 2013

Available online 1 March 2013

\section{Keywords:}

Frame corners

Reinforced concrete

Stress fields

Strut-and-tie modelling

Testing

\begin{abstract}
A B S T R A C T
The strength and deformation capacity of concrete frames is typically governed by their nodal regions behaviour. This is particularly relevant for frame corners subjected to opening bending moments, where premature brittle failures may develop depending on the reinforcement arrangement. Although some previous investigations have shown a significant dependence of the nodal regions behaviour as a function of the corner angle ( $\alpha$, measured between frame axes), most research has concentrated on orthogonal corners $\left(\alpha=90^{\circ}\right)$. However, design recommendations obtained for orthogonal corners may not be directly applicable (neither optimal) for other corner angles, and particularly for larger corner angles. In this paper, the result of an experimental and theoretical investigation on frame corners with a corner angle $\left(\alpha=125^{\circ}\right)$ is presented. Sixteen tests were performed on $400-\mathrm{mm}$ thickness specimens representative of actual frame corners subjected to opening bending moments. The experimental results are investigated by means of Elastic-Plastic Stress Fields and strut-and-tie models leading to a number of recommendations for their design in practice.
\end{abstract}

(c) 2013 Elsevier Ltd. All rights reserved.

\section{Introduction}

A large number of RC structures present regions of discontinuity where beam theory is not suitable for design of the reinforcement [1]. This is for instance the case of nodal regions of frames, stairs, cut-and-cover tunnels, retaining walls, silos or folded structures (refer to Fig. 1). The behaviour of nodal regions is highly dependent on the reinforcement arrangement which ensures the transfer of inner forces and typically governs the strength and deformation capacity of the structure [2]. The use of suitable reinforcement arrangements is thus instrumental for the overall structural behaviour and many research efforts have been devoted in the past to this topic. For corner frames, these researches have most focused on members subjected to closing (Fig. 2a) or to opening corners (Fig. 2b). Research has been founded on experimental works [3-27] and some design approaches have been proposed on their basis, mostly based on lower-bound solutions of the theory of plasticity (strut-and-tie modelling [1,28,29], refer to Fig. 2c, or stress fields [29-31], refer to Fig. 2d) as well as grounded on finite element modelling [32-34]. The strength and deformation capacity of nodal regions of reinforced concrete frames has also been a topic of investigation related to the cyclic (seismic) behaviour of frames. A detailed state-of the-art on this matter can be consulted elsewhere [35-37].

\footnotetext{
* Corresponding author. Tel.: +41 21693 2889; fax: +41 216935884.

E-mail address: miguel.fernandezruiz@epfl.ch (M. Fernández Ruiz).
}

\subsection{Behaviour of orthogonal nodal regions}

Most existing tests [3-27] on nodal regions of frames have been performed on orthogonal geometries $\left(\alpha=90^{\circ}\right)$. Fig. 2e and f show the mechanical performance of the nodal regions (subjected to closing or to opening bending moments respectively) by means of the ratio between the bending moment at failure $\left(M_{R}\right)$ and the theoretical bending strength $\left(M_{\text {flex }}\right)$ calculated according to the theory of plasticity:

$M_{f l e x}=\rho \cdot b \cdot d^{2} \cdot f_{y} \cdot\left[1-\frac{\rho \cdot f_{y}}{2 \cdot f_{c p}}\right]$

where $\rho$ refers to the geometrical reinforcement ratio (cross-sectional area of the reinforcement divided by the width and effective depth of the section), $f_{y}$ refers to the yield strength of the reinforcement and $f_{c p}$ to the plastic strength of concrete $\left(f_{c p}=f_{c} \cdot \eta_{f c}\right.$, where $f_{c}$ is the compressive strength of concrete measured in cylinder and $\eta_{f c}$ a brittleness factor $\left.[29,30]: \eta_{f c}=\left(30 / f_{c}[\mathrm{MPa}]\right)^{1 / 3} \leqslant 1\right)$.

A relatively quite large scatter on the results is observed (refer to Fig. 2e and f). This is due to the significant influence of the reinforcement layout on the overall behaviour (detailed analyses for each reinforcement detail will be commented later). For specimens with large amounts of secondary reinforcement $[18,26]$ or with significant hardening of the flexural steel, the measured strength may be larger than the calculated bending strength as only the principal flexural reinforcement of the nodal region is accounted 


\section{Nomenclature}

$A_{s} \quad$ cross-sectional area of flexural bars

$A_{\text {swn }} \quad$ cross-sectional area of transversal reinforcement in the nodal region

$b \quad$ width of the member

$d \quad$ effective depth of the member

$F_{c} \quad$ force in the compression chord

$F_{c 1}, F_{c 2}, F_{c 3}$ force in inclined compression struts (refer to the presented strut-and-tie models)

$F_{s} \quad$ force in the tension chord

$F_{w} \quad$ half the force in the transversal reinforcement in the nodal region

$f_{c} \quad$ compressive strength of concrete (measured in cylinder)

$f_{c p} \quad$ compressive plastic strength of concrete

$f_{c t} \quad$ tensile strength of concrete (measured in cylinder)

$f_{y} \quad$ yield strength of flexural reinforcement steel

$f_{y w} \quad$ yield strength of transversal reinforcement steel

$f_{y w n} \quad$ yield strength of steel transversal reinforcement steel in the nodal region

$h \quad$ height of the member

$M \quad$ bending moment

$M_{E P S F} \quad$ bending strength predicted by Elastic-Plastic Stress Fields method

\begin{tabular}{|c|c|}
\hline$M_{\text {flex }}$ & bending strength \\
\hline$M_{R}$ & bending moment at failure \\
\hline$M_{\Delta 0}$ & $\begin{array}{l}\text { bending moment acting in the specimen corresponding } \\
\text { to a significant change on the stiffness of the member }\end{array}$ \\
\hline$M_{\Delta 20}$ & $\begin{array}{l}\text { bending moment acting in the specimen corresponding } \\
\text { to an increasing of the relative rotation } \psi_{\text {rel }}=20 \mathrm{mRad} \\
\text { from the point corresponding to } M_{\Delta 0}\end{array}$ \\
\hline Q & applied load \\
\hline$s_{w n}$ & length of the diagonal of the nodal region \\
\hline$w_{\text {avg }}$ & average crack width in the nodal region \\
\hline$w_{\max }$ & maximal crack width in the nodal region \\
\hline$z$ & lever arm of the inner forces \\
\hline$\alpha$ & corner angle \\
\hline$\delta$ & vertical displacement \\
\hline$\eta_{f_{c}}$ & brittleness factor \\
\hline$\xi$ & $\begin{array}{l}\text { ratio of the tension force } F_{s} \text { deviated by the flexural rein- } \\
\text { forcement }\end{array}$ \\
\hline$\rho$ & Geometrical reinforcement ratio $\rho=A_{s} /(b \cdot d)$ \\
\hline$\rho_{\mathrm{wn}}$ & $\begin{array}{l}\text { Geometrical reinforcement ratio of the nodal region } \\
\rho_{w n}=A_{s w n} /\left(b \cdot s_{w n}\right)\end{array}$ \\
\hline$\psi_{r e}$ & relative rotation of the nodal region \\
\hline
\end{tabular}

detailing of the CCT nodes [29] (Fig. 2d, one tension chord in equilibrium with two compression struts). This justifies the significantly large scatter of test results (Fig. 2f), with rather sensitive performances depending on the anchorage conditions (development, mechanical devices, etc.) and on the presence or not of a reinforcement to control crack widths developing through the diagonal compression struts of the nodal region.

A more detailed analysis of the results for the opening corners as a function of the reinforcement layout is shown in Fig. 3. Five reinforcement arrangements are considered for the flexural bars (A to E, refer to Fig. 3b and f respectively) as well as four for the secondary reinforcement arrangements $(\mathrm{a}-\mathrm{d})$ :

- In comparison to Fig. 2f, the scatter of the results is reduced for each reinforcement layout (flexural and secondary) although it is still significant. (a)

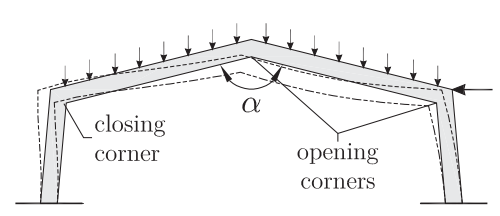

(b)

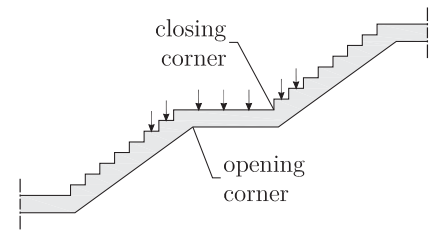

(c)

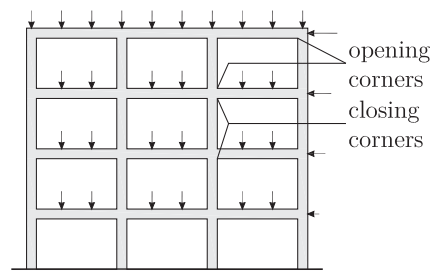

(d)

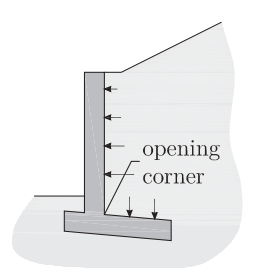

(e)

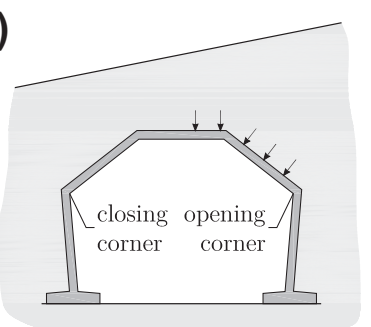

(f)

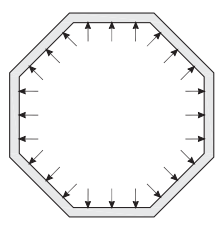

(g)

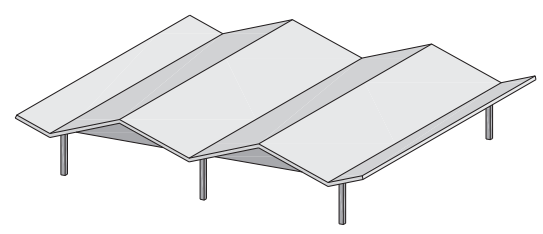

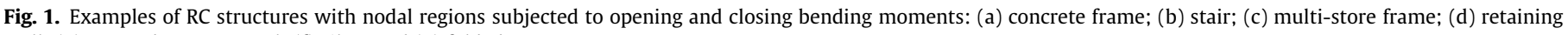
wall; (e) cut-and-cover tunnel; (f) silos; and (g) folded structure. 
(a)

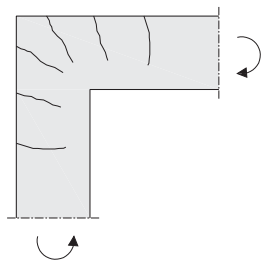

(c)
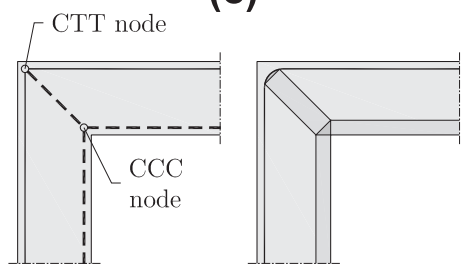

(e)

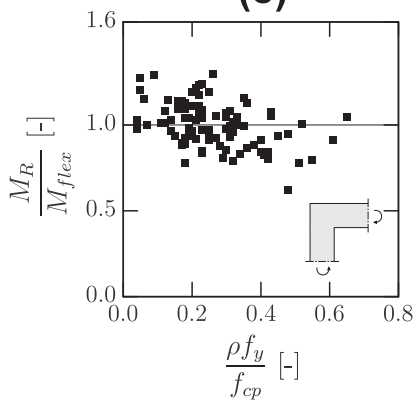

(b)

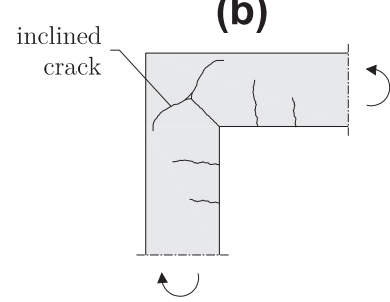

(d)

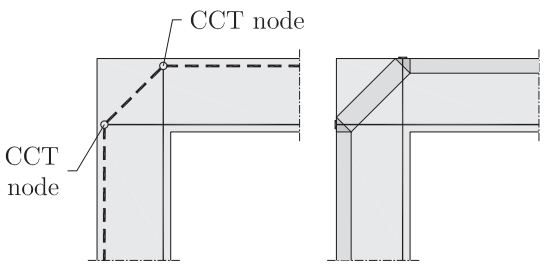

(f)

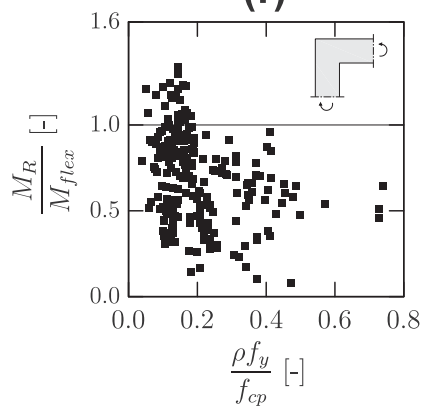

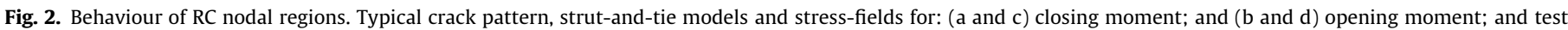
results [3-27]; (e) for closing moments (94 tests) and (f) for opening moment (230 tests).

(a)

Flexural reinforcement layout
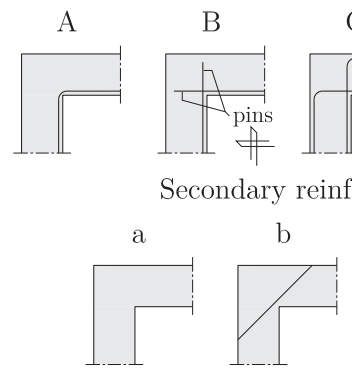

(c)

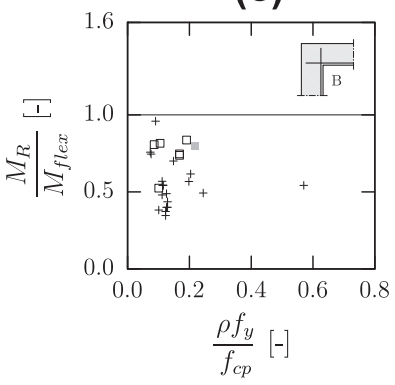

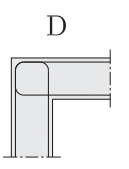

ment layout
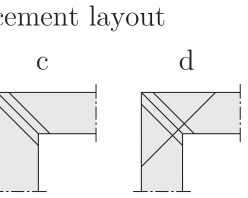

(d)

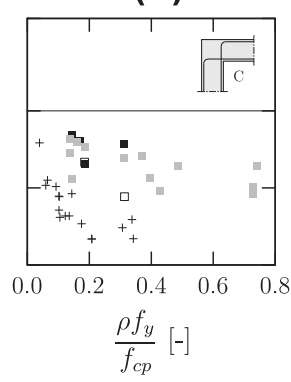

(b)

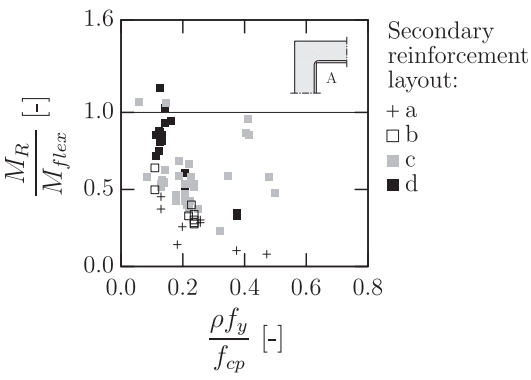

(e)

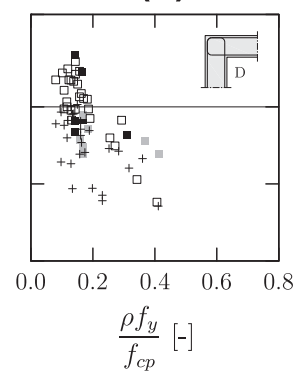

(f)

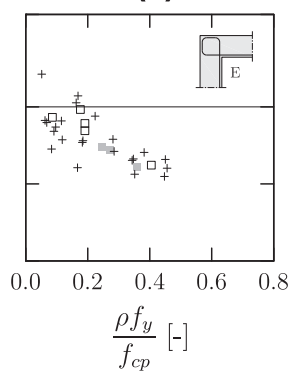

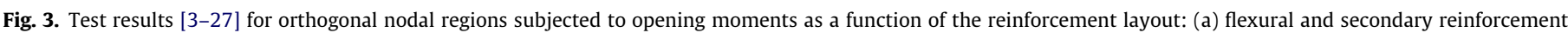
layouts; (b) flexural reinforcement type A (68 tests); (c) type B (27 tests); (d) type C (37 tests); (e) type D (67 tests); and (f) type E (31 tests). 
- The performance of the nodal region is generally improved with the addition of a secondary reinforcement for crack control or for deviation of compression struts.

- The best performances are in general obtained for flexural reinforcement layouts D and E (Fig. 3e and f). These solutions are nevertheless difficult to be used in practice due to the bents and hooks required for the flexural bars.

- The worst performances are in general obtained for the flexural arrangement type $\mathrm{C}$ (flexural bars developed in the compression chords [29], Fig. 3d), which is however, very simple to be arranged in practice. Also, very poor performances are obtained for detail Aa (continuous flexural reinforcement without secondary reinforcement, Fig. 3b).

\subsection{Behaviour of non-orthogonal nodal regions}

In contrast to the large amount of tests performed for orthogonal nodal regions, a more limited amount of tests $[3-5,11,20]$ have been performed for other values of the nodal angle and in all cases for members with low thicknesses (lower than $200 \mathrm{~mm}$, which may overestimate the strength of thick members in case the tensile strength of concrete is governing). However, such geometries are frequently found in practice, normally with larger values of such angle $\left(\alpha>90^{\circ}\right.$, refer to Fig. 1$)$ and in many cases for thicker members.

The available results (refer to Fig. 4) show that all of the previous conclusions for orthogonal nodal regions are not directly applicable to other angles of the nodal regions. For instance, reinforcement details type $\mathrm{C}$ and $\mathrm{D}$ (where tests are available) show minimum performance for corner angles in between $90^{\circ}$ and $120^{\circ}$ (refer to Fig. 4c-e), but these details can be reasonable and justified in other cases (larger or smaller corners angle). On the contrary, other conclusions (as the positive influence of arranging a secondary reinforcement or the poor performance of members with high mechanical reinforcement ratio) are still applicable (refer to Fig. 4a and b).

It is to be noted that the available tests show an increased (and satisfactory) performance of detail type $C$ for larger values of the nodal region $\left(\alpha>90^{\circ}\right)$. This detail is simple to be built but was

(a)

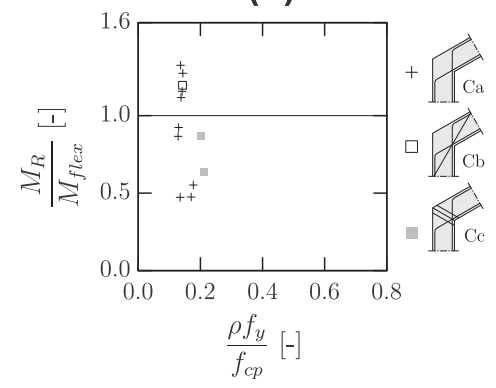

(c)
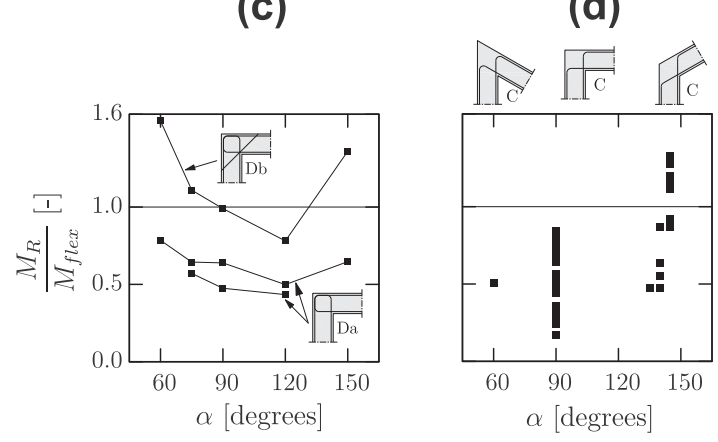

found to be mechanically unsatisfactory for orthogonal geometries. However, for larger nodal region angles, it can be considered as an interesting solution for construction and from a mechanical point of view. In this paper, the possibility of using such reinforcement arrangement (type $\mathrm{C}$ ) in combination with a secondary reinforcement is investigated by means of a specific test series. The results confirm the pertinence of this approach. On this basis, a design method is proposed by using lower-bound solutions of the theory of plasticity (stress fields and strut-and-tie models).

\section{Experimental programme}

The experimental programme described below continues a preliminary research performed by the authors on the behaviour of nodal regions. The results of the preliminary research are presented elsewhere [39] and showed the problematic behaviour of TTT nodes [29] (nodes where only tension ties are linked) that were therefore avoided in the present testing programme.

\subsection{Specimens}

A total of sixteen specimens with a nodal angle $\alpha=125^{\circ}$ were tested presenting various reinforcement details. All specimens were investigated under pure bending conditions in the nodal region (by using a four-point bending test setup, refer to Fig. 5a). The cross-section was identical for all members $(300-\mathrm{mm}$ width and $400-\mathrm{mm}$ height) as well as the nominal reinforcement ratio ( $\rho=0.7 \%$, corresponding to two $22-\mathrm{mm}$ diameter bars). The nominal concrete cover for the flexural reinforcements was $29 \mathrm{~mm}$, leading to a nominal effective depth $d=360 \mathrm{~mm}$. Continuous compression reinforcement ( 2 bars $22-\mathrm{mm}$ diameter) bent in the corner region and sufficient stirrups to avoid shear failures outside the investigated region were provided for all specimens (Fig. 5b). With respect to the flexural reinforcement, four different layouts were investigated corresponding to details B, C and two alternatives for layout $\mathrm{D}$ (named $\mathrm{D}_{1}$ and $\mathrm{D}_{2}$ in the following), see Fig. $5 \mathrm{c}$. These details were used alone or in combination with a secondary reinforcement (details a, b and $c_{1}$ to $c_{5}$, Fig. $5 d$ ) and/or transversal

(b)

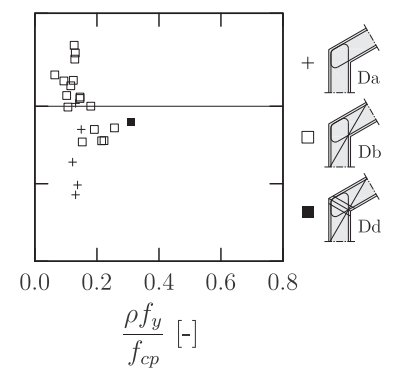

(e)

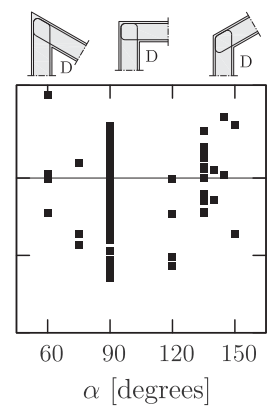

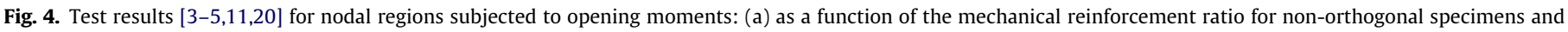
reinforcement type C (12 tests); (b) type D (23 tests); (d) as a function of the nodal region angle for reinforcement type C (50 tests); and (c and e) type D (97 tests). 
(a)

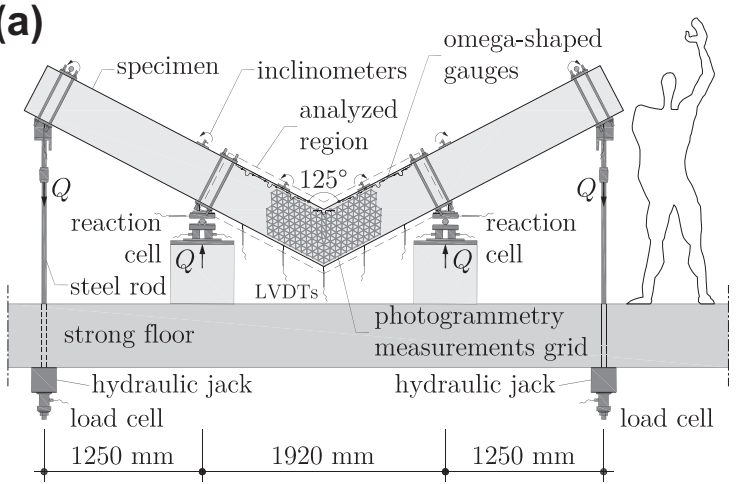

(b)

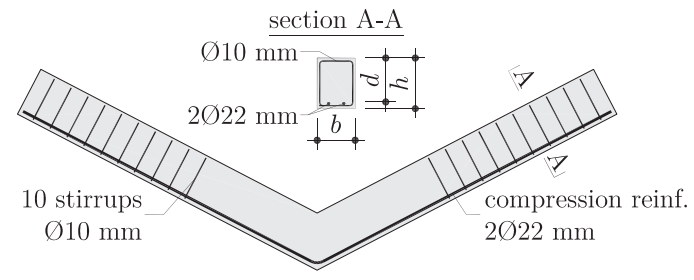

(c)

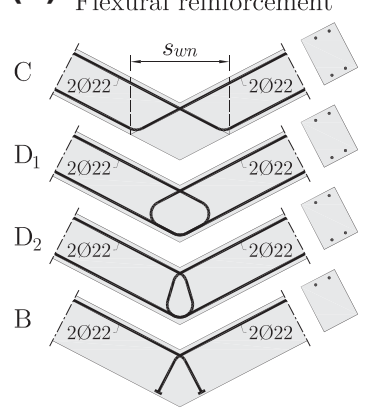

(e)

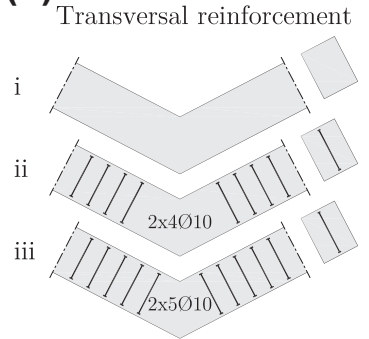

(d) Secondary reinforcement
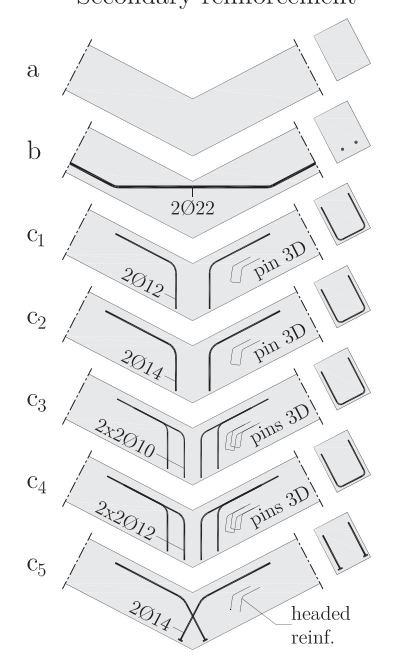$$
\text { (1) }
$$

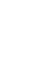

Fig. 5. Experimental programme: (a) test setup; (b) compression reinforcement and stirrups; (c) flexural reinforcement layout; (d) secondary reinforcement; and (e) transversal reinforcement.

reinforcement in the nodal region (types i to iii, Fig. 5e). More details concerning the investigated reinforcement layouts (area, position, diameter and bend radius of reinforcements) are given in Fig. 6 and Table 1.

The 16 specimens were tested within two series investigating the following aspects:

- The first series (refer to the left hand-side column of Fig. 6) was tested to investigate the performance of the flexural reinforcement layouts (specimens SC22, 26, 30, 34). Four additional specimens were also tested to investigate the influence of placing an additional straight flexural reinforcement (type b, specimens SC23, 27, 31, 35).
- The second series (refer to the right hand-side column of Fig. 6) was also composed of eight specimens and was tested to identify the influence of the various secondary (transversal) reinforcement arrangements on the performance of the nodal regions. This research concentrated only on type $C$ flexural reinforcement, which was selected as the best synthesis between constructability and potential mechanical performance when a transversal reinforcement is provided (refer to Fig. 3d).

\subsection{Material properties}

The specimens were cast in 2 batches with normal strength concrete. Its compressive strength $f_{c}$ at the time of testing ranged between 40.5 and $42.1 \mathrm{MPa}$ for specimens SC22 to SC35 and between 30.8 and $31.3 \mathrm{MPa}$ for specimens SC38 to SC45 (refer to Table 1 ). The tensile strength of concrete $f_{c t}$ was obtained by direct tension tests (on cylinders with a diameter of $160 \mathrm{~mm}$ and a height of $320 \mathrm{~mm}$ ) and was measured after 28 days (Table 1). The maximum aggregate size of concrete was $16 \mathrm{~mm}$. The longitudinal reinforcement ( 2 bars diameter $22 \mathrm{~mm}$ ) was hot-rolled steel with a well-defined yield plateau $\left(f_{y}\right)$ ranging between 500 and $515 \mathrm{MPa}$. The secondary reinforcement (diameters 10,12 and $14 \mathrm{~mm}$ ) was cold-worked with a nominal (0.2\% residual strain) yield strength between 555 and $575 \mathrm{MPa}$. For details on each specimen, please refer to Table 1.

\subsection{Test setup}

The same test setup was used for all specimens; see Fig. 5a. The simply supported specimens were loaded under four-point bending. The size of all loading plates was $300 \times 150 \times 20 \mathrm{~mm}$ (Fig. 5a). The central span (distance between the two inner supports axes) was $1920 \mathrm{~mm}$, and the loads (Q) were applied at $1250 \mathrm{~mm}$ of each support (Fig. 5a). Horizontal movements were possible at the loading points. The two supports allowed rotations and once of them the horizontal sliding. The investigated region of the specimens was situated within the central zone (where the bending moment was constant and no shear force was acting).

\subsection{Measurements}

Systematic measurements were performed for all specimens in the investigated region (Fig. 5a):

- Vertical displacements $(\delta)$ measured by means of displacement transducers.

- Strains at concrete surface were recorded at the level of the flexural bars by means of omega-shaped gages.

- Six inclinometers recorded the nodal region relative rotation $\left(\psi_{\text {rel }}\right)$.

- Photogrammetric measurements were performed on one side of the specimen to track the development of cracks and their widths during testing.

\section{Discussion of test results}

Fig. 6 include a sketch of the reinforcement layouts and the observed crack pattern at failure (maximal load) for all specimens.

\subsection{Performance of the reinforcement layouts}

A number of parameters are used in the following to assess the performance of the various reinforcing details (see values in Table 1 and Fig. 6): 


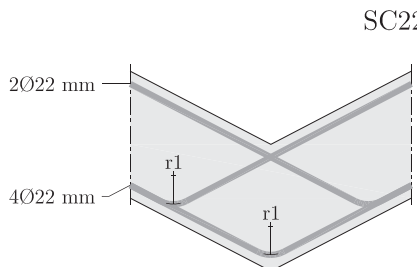

SC22 (Cai)

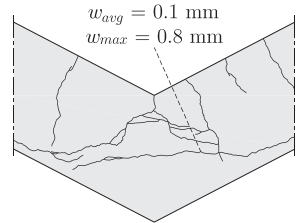

SC23 (Cbi)
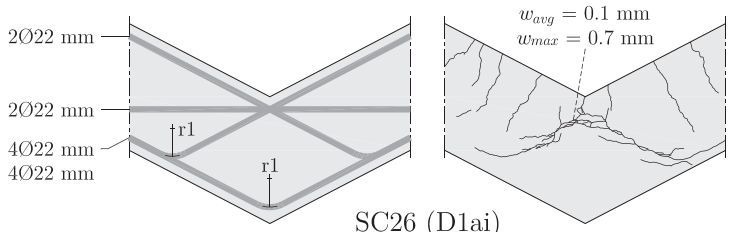

SC26 (D1ai)
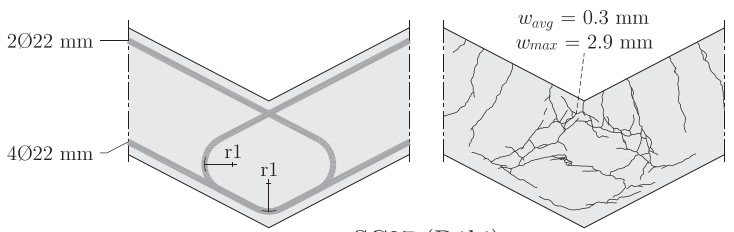

$\mathrm{SC} 27$ (D1bi)
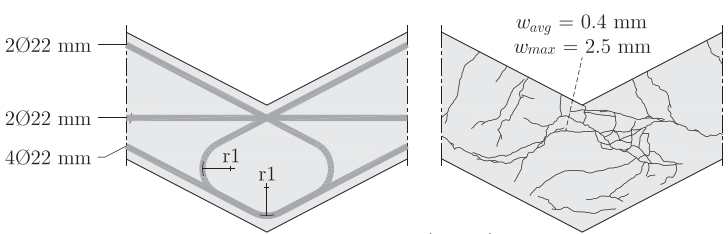

SC30 (D2ai)
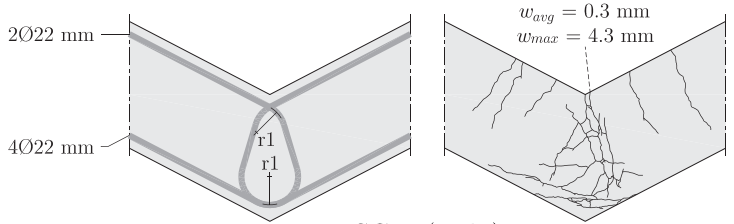

SC31 (D2bi)
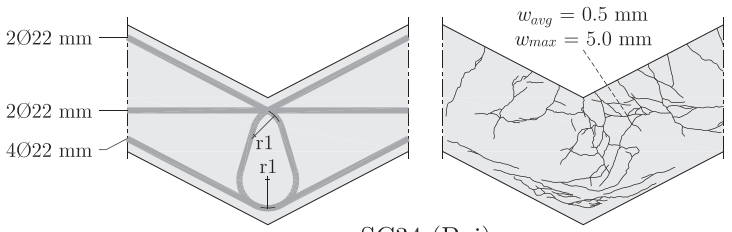

SC34 (Bai)
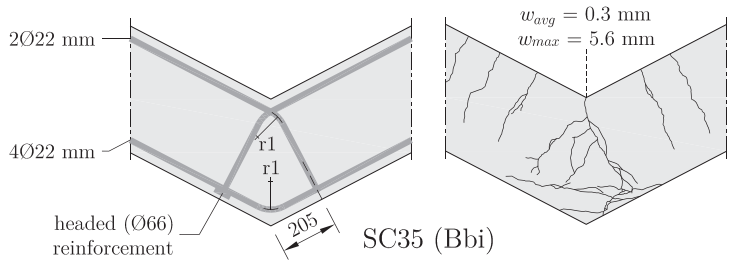

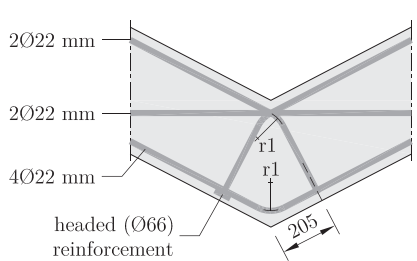

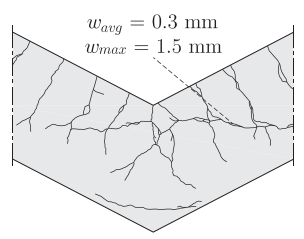

SC38 (Cc1ii)
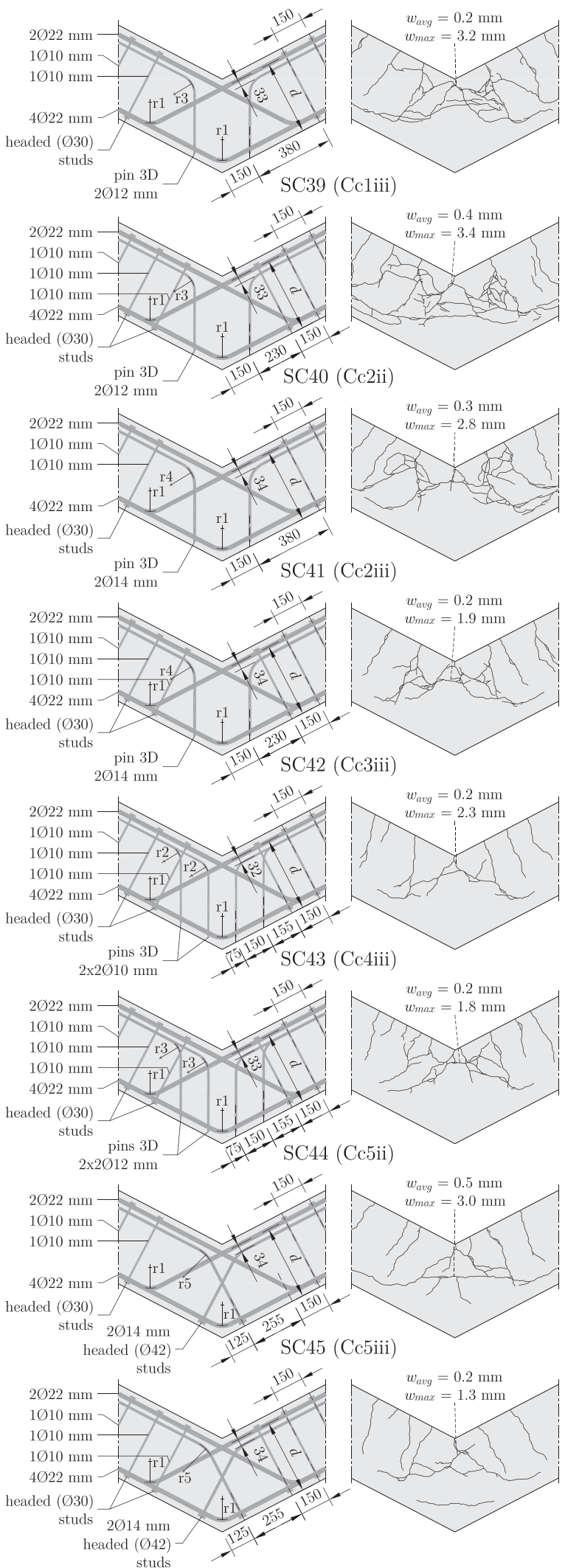

bent radius: $\mathrm{r}_{1}=101 \mathrm{~mm} ; \mathrm{r}_{2}=80 \mathrm{~mm} ; \mathrm{r}_{3}=96 \mathrm{~mm} ; \mathrm{r}_{4}=112 \mathrm{~mm} ; \mathrm{r}_{5}=150 \mathrm{~mm}$; 


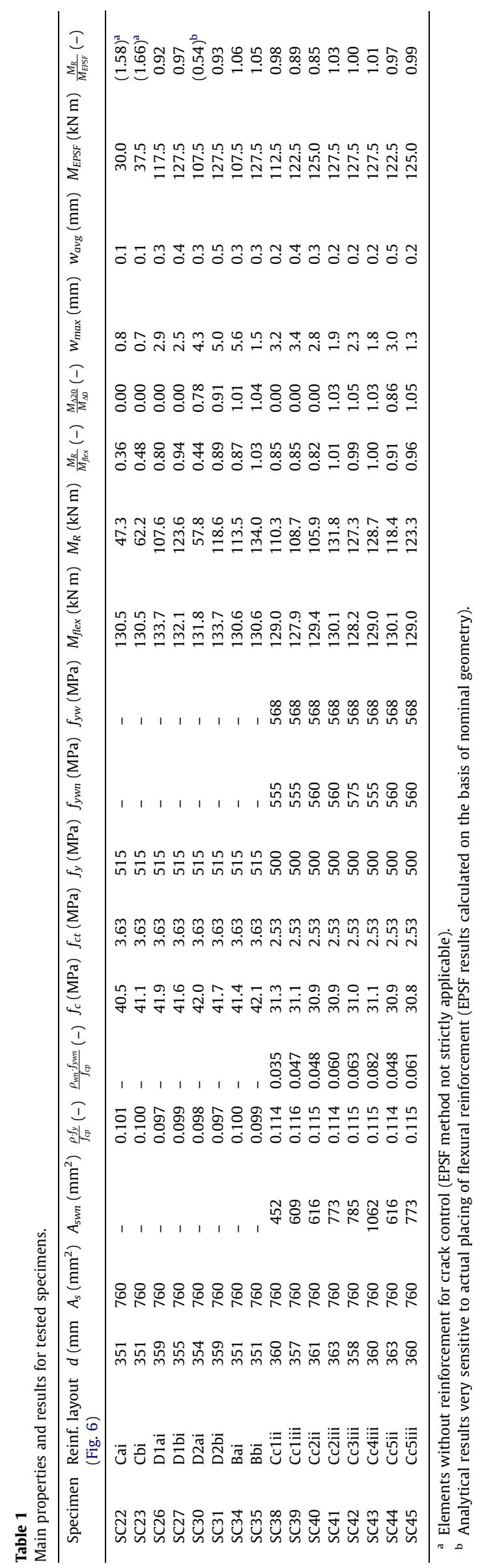

- The strength performance can be quantified by the ratio between the bending moment at failure $\left(M_{R}\right)$ and the theoretical bending strength $\left(M_{\text {flex }}\right)$. Values of this ratio are summarised in Table 1.

- The deformation capacity is quantified by the ratio between the bending moments $M_{\Delta 20}$ and $M_{\Delta 0}$. The bending moment $M_{\Delta 0}$ indicates the point where a significant change on the stiffness of the member is recorded (due to yielding of the flexural reinforcement or due to failure within the nodal region). The bending moment $M_{\Delta 20}$ is that still acting in the specimen after an increasing equal to $20 \mathrm{mRad}$ of the relative rotation $\left(\psi_{\text {rel }}\right)$ from the point previously mentioned. A value of this ratio larger or equal than one indicates thus a plastic or hardening behaviour, whereas a value smaller than one indicates a softening or brittle behaviour. Values of this ratio are summarised in Table 1.

- The photogrammetric measurements were used to describe the observed crack pattern. The maximal crack width $\left(w_{\max }\right)$ and the average crack width ( $w_{\text {avg }}$, calculated taking into account each triangles of the grid where a crack was recorded) are summarised in Table 1 and Fig. 6. The given values were recorded when the bending moment $M_{\Delta 0}$ aforementioned was acting. These values allow estimating the extent and the localisation of the cracking in the nodal region.

\subsection{Influence of flexural reinforcement layout}

The behaviour of the four investigated flexural reinforcement arrangements (specimens without transverse reinforcement) is compared in Fig. 7a. Details $\mathrm{D}_{1}$ (SC26) and B (SC34) exhibit the best performances, whereas details type $\mathrm{C}(\mathrm{SC} 22)$ and $\mathrm{D}_{2}$ (SC30) show a rather poor performance. With the addition of a straight bar across the connection (Fig. 7b), the performance of the joints was improved in terms of their strength and deformation capacity. This was particularly the case for types $\mathrm{B}$ (SC35), $\mathrm{D}_{1}(\mathrm{SC} 27)$ and $\mathrm{D}_{2}$ (SC31), where the strength was equal, or very close to, the plastic strength. However, detail type C (SC23) only increases its strength in a limited manner, still exhibiting a poor performance with limited strength $\left(M_{R} / M_{\text {flex }}<1\right)$ and brittle behaviour, see Table 1 .

It is interesting to note the significant improvement on the strength of detail $\mathrm{D}_{2}$ (specimens SC30 and SC31). This detail, without the additional straight flexural reinforcement is rather sensitive to the actual placing of the bars. However, once a secondary flexural reinforcement is arranged, the detail is less sensitive and exhibits a strength and behaviour comparable to the other type D ( $D_{1}$, specimens SC26-27) and B (SC34-35).

\subsection{Influence of secondary reinforcement arrangement}

After analysis of the behaviour of reinforcing details B, C, D 1 and $D_{2}$, it was decided to investigate more in detail if detail type $C$ (the easiest to be constructed but with poor mechanical performances) could be sufficiently improved with addition of secondary transversal reinforcement in the nodal region. To that aim, the aforementioned transversal reinforcement arrangements were tested (8 additional specimens). The results of these tests are shown in Fig. $7 \mathrm{c}$ and $\mathrm{d}$. These results show that the behaviour of detail $\mathrm{C}$ can be effectively improved with the addition of transversal reinforcement. Despite the fact that several details were investigated, the parameter showing the most significant influence was the total amount of available transversal reinforcement suitably developed rather than its actual arrangement or detailing. The amount of transversal reinforcement is characterised by the mechanical transversal reinforcement ratio $\rho_{w n} \cdot f_{y w n} \mid f_{c p}$, where $\rho_{w n}=A_{s w n} /$ $\left(b \cdot s_{w n}\right)$ is calculated accounting for the area $\left(A_{s w n}\right)$ of all transversal reinforcement suitably developed (Fig. $5 \mathrm{~d}$ and e) and placed within the diagonal of the nodal region $\left(s_{w n}=d / \cos (\alpha / 2)\right.$, see Fig. $\left.5 c\right)$. 
As Fig. 7c and d show, specimens with $\rho_{w n} \cdot f_{y w n} / f_{c p} \geqslant 0.06$ (Fig. 7d) have a satisfactory behaviour both in terms of strength and deformation capacity, whereas values $\rho_{w n} \cdot f_{y w n} / f_{c p}<0.06$ (Fig. 7c) still lead to insufficient strength and brittle behaviour (see in details Table 1 and Fig. 6). It is to be noted that increasing the amount of transversal reinforcement above $\rho_{w n} \cdot f_{y w n} / f_{c p}=0.06$ (refer to specimen SC43) leads in fact to none additional improvement on the mechanical behaviour for the investigated flexural reinforcement amount.

\section{Analysis of opening corners based on lower-bound solutions of the theory of plasticity}

\subsection{Analysis of specimens using the Elastic-Plastic Stress Field method} (EPSF)

A suitable manner to investigate and to design regions of discontinuity of RC structures is by developing lower-bound solutions of the theory of plasticity [1,28-31] such as stress fields or strutand-tie models. A consistent approach for automated development of Elastic-Plastic Stress Fields (EPSFs) based on the finite element method was presented by the authors elsewhere [30]. It allows obtaining suitable stress fields in equilibrium with the external actions, accounting for compatibility conditions and for the influence of transversal concrete cracking on the strength of concrete in compression. A detailed description of the EPSF method, extensive validation against test results and applications to practical cases can be consulted elsewhere $[30,31,39]$. These studies show that the EPSF is a reliable tool if the basic conditions for development of a stress field (availability of a minimum reinforcement for crack control) are respected [30]. As an example of such accuracy, Fig. 8a shows a comparison of EPSF results with the actual cracking pattern measured in specimen SC42, showing identical measuredto-calculated strength and failure mode.

The sixteen specimens presented in this paper were investigated by means of EPSF. The results are summarised in Table 1:

- For specimens SC22 and 23, without any transverse reinforcement and with poor performances (average ratio $M_{R}$ / $M_{\text {flex }}=0.42$ ), the EPSF is not strictly applicable (lack of reinforcement for crack control) and provides thus safe estimates of the

(a)

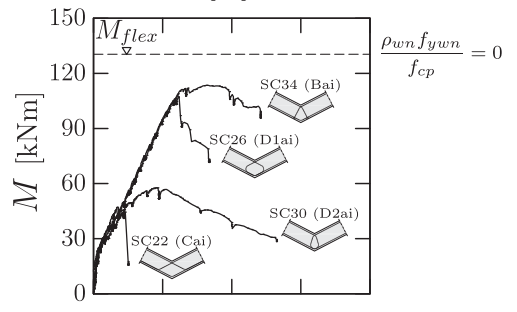

(c)

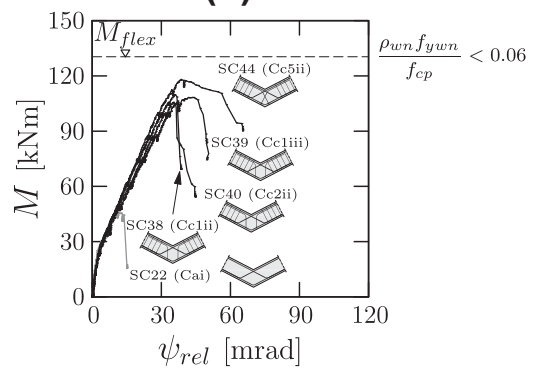

strength. This is justified [30] since the performance of these details relies much on the tensile strength of concrete which is neglected in the EPSF analyses.

- For specimens with $\rho_{w n} \cdot f_{y w n} / f_{c p}<0.06$ (average ratio $M_{R} /$ $M_{\text {flex }}=0.94$, specimens provided with a minimal amount of secondary reinforcement in the nodal region or with flexural reinforcement with suitably developed hooks: SC26-27, 31,34-35,38-40 and 44) the results are rather good by using EPSF. The average value of the measured-to-predicted strength is equal to 0.94 with a low scatter of results (Coefficient of Variation equal to 7\%). These values do not account for test SC30 whose measured strength was significantly low due to its sensitivity to actual placing of the reinforcement (refer to crack pattern of Fig. 6)

- For the other specimens with $\rho_{w n} \cdot f_{y w n} / f_{c p} \geqslant 0.06$ (SC41-43 and 45 with average ratio $M_{R} / M_{\text {flex }}=1.00$ ), the transverse reinforcement allowed for a very good control of cracks in the failure region and all failed in bending. The EPSF also capture this behaviour (average measured-to-calculated strength of 1.01 and a $\mathrm{CoV}$ of $2 \%$ (see for instance comparison for specimen SC42 in Fig. 8a).

Accounting for these results, the EPSF has been used to calculate the minimum amount of transverse reinforcement that should be provided in nodal regions subjected to opening moments to ensure that failure develops by yielding of the flexural reinforcement. For the tests presented in this paper, (refer to Fig. 8b, solid line) it suitably predicts the limit of the required mechanical transverse reinforcement ratio $\left(\rho_{w n} \cdot f_{y w n} / f_{c p}\right)$ as a function of the mechanical flexural reinforcement ratio $\left(\rho \cdot f_{y} / f_{c p}\right)$. All points above that line indicate that failure follows by yielding of the flexural reinforcement $\left(M_{R} / M_{\text {flex }} \approx 1\right)$ whereas all points below that line indicate failure by concrete spalling, anchorage failure or stirrup yielding. The same happens for other tests available in the scientific literature $[11,17]$ on reinforcement details type Cc or Cd (Fig. 8c-e).

\subsection{Design of nodal regions by means of strut-and-tie models}

For design of such members, a numerical approach as the EPSF is possible but not always convenient. For such case, strut-and-tie models (STMs) or rigid-plastic stress fields [29] can efficiently be

(b)

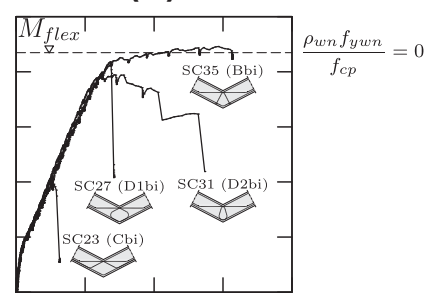

(d)

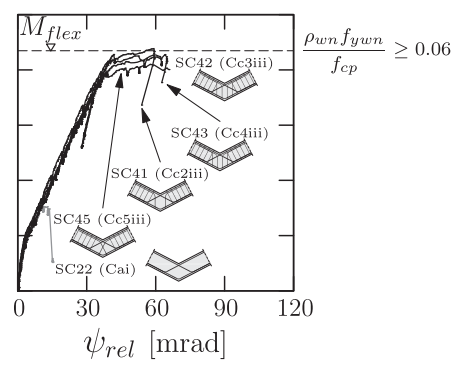

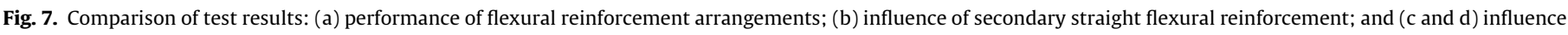
of secondary transversal reinforcement on type $C$ layout. 


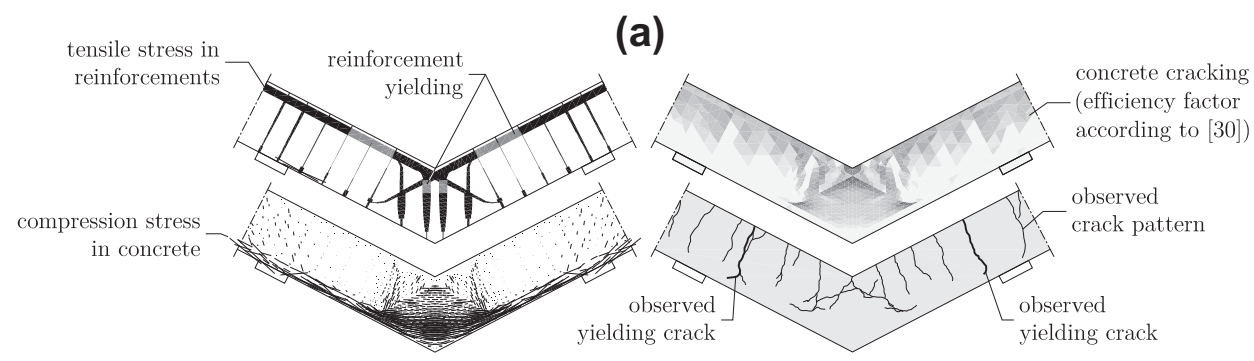

(b)

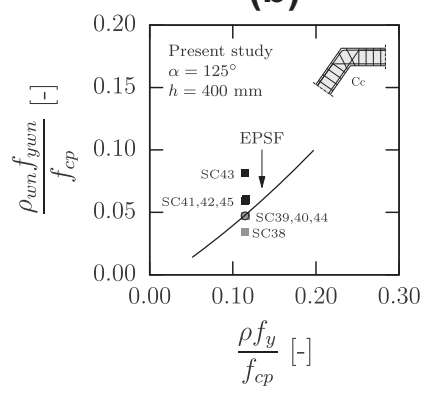

(c)

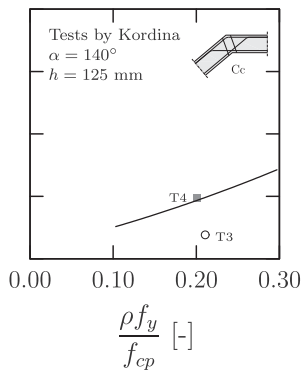

(d)

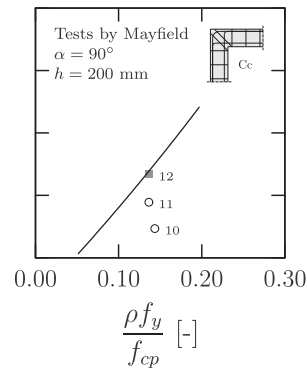

(e)

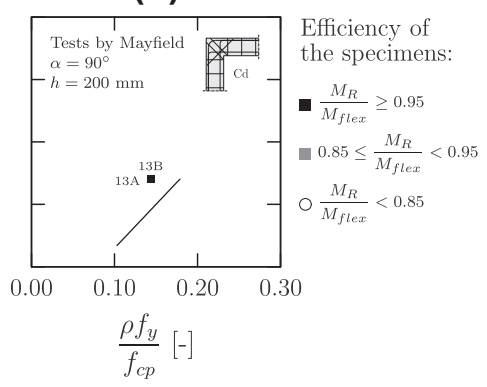

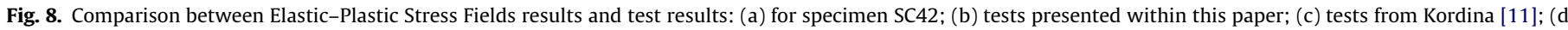
and e) tests from Mayfield et al. [17].

(a)

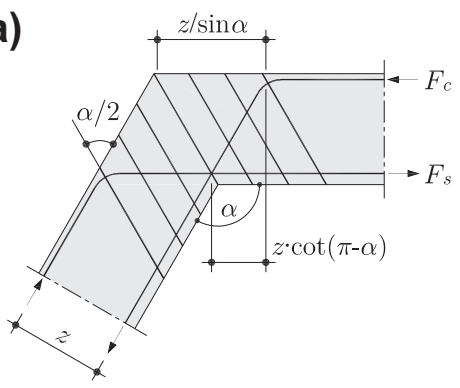

(b)
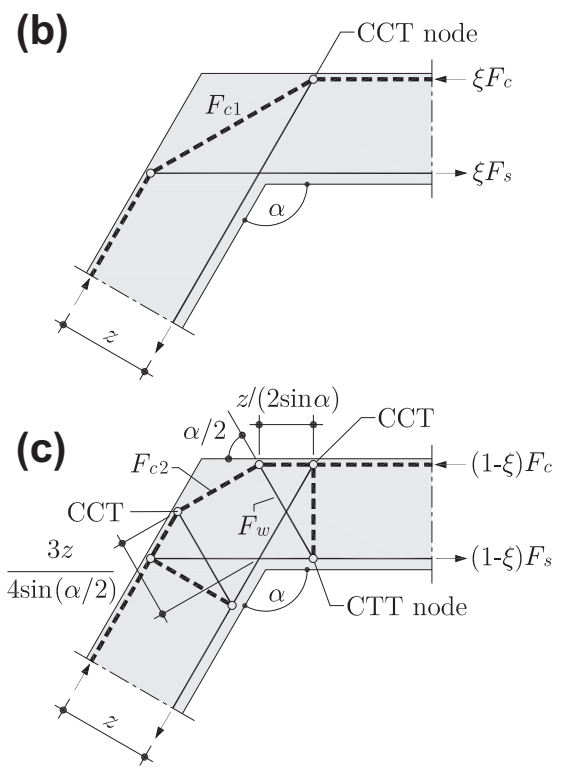

(d)
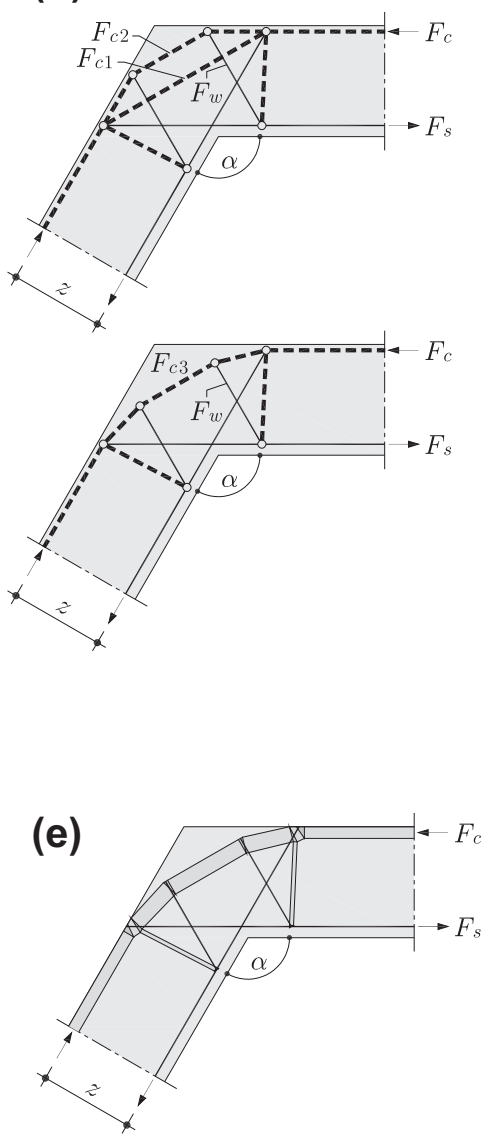

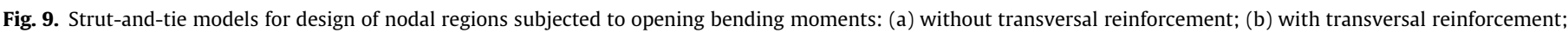
(c) combination of previous models; (d) corresponding rigid-plastic stress field. 
(a)

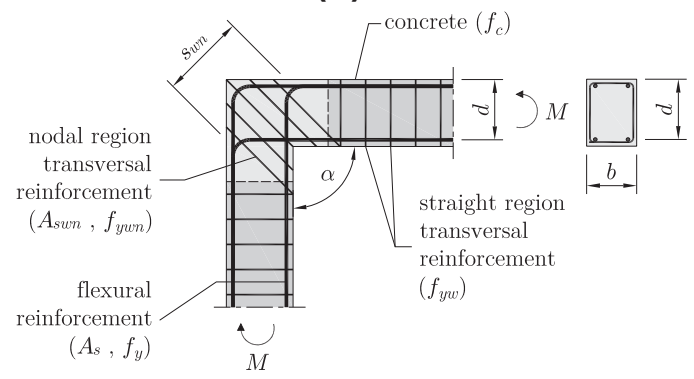

(b)

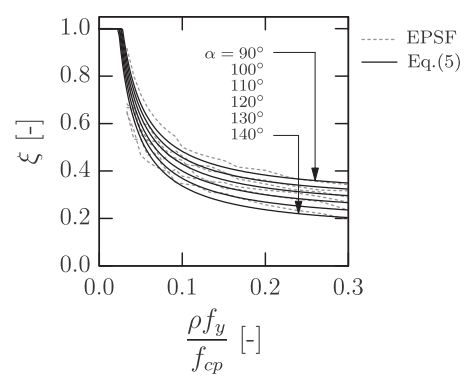

(c)

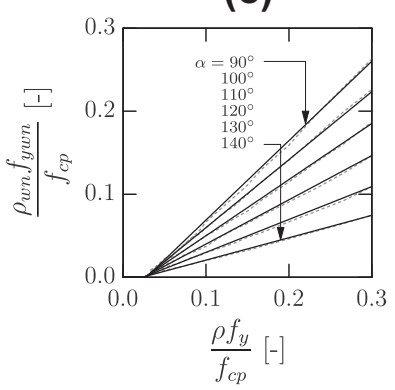

(d)

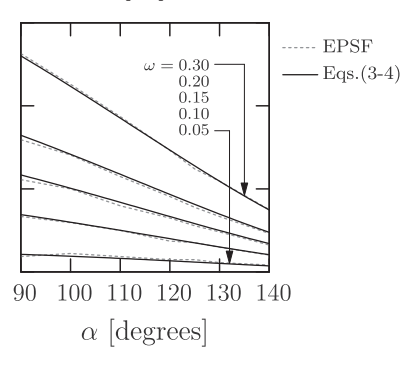

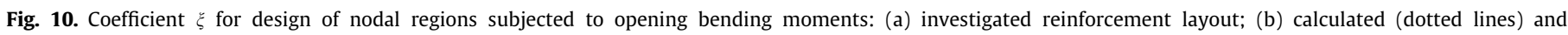
approximated (solid line) values of coefficient $\xi$; (c-d) abaci for design of transversal reinforcement.

used. In this section, suitable models will be investigated on the basis of the previous EPSF results, focusing on design of the transversal reinforcement (see Fig. 9a) of detail C (that was identified as the easiest to be constructed in practice and showing satisfactory performances if minimum amount of transversal reinforcement is provided).

A suitable STM for this region can be developed by combining two basic models. The first (refer to Fig. 9b) requires no transversal reinforcement for deviating the inner compression forces by the bending reinforcement. Nevertheless, as experimentally observed, this leads to poor performances and potentially brittle failures with crack localisation. The second (Fig. 9c) requires for deviation of the inner forces the arrangement of a transversal reinforcement. The forces in the tension chord $\left(F_{s}\right)$ and in the compression chord $\left(F_{c}=F_{S}\right)$ are thus partly $\left(\xi \cdot F_{S}\right)$ deviated by the former model and partly $\left((1-\xi) \cdot F_{s}\right)$ by the latter (Fig. 9b and $\left.c\right)$. The actual behaviour of the region will thus be a combination of both models (Fig. 9d).

The chord forces for reinforcement yielding can be calculated as:

$F_{c}=F_{s}=\rho \cdot b \cdot d \cdot f_{y}$

The required force for the transversal reinforcement $\left(F_{w}\right)$ arranged in the nodal zone (according to Fig. 9a and c) can thus be calculated by equilibrium conditions for the geometry of Fig. 9c as:

$F_{w}=(1-\xi) \cdot \frac{4}{3} \cdot \rho \cdot b \cdot d \cdot f_{y} \cdot \cos \left(\frac{\alpha}{2}\right)$

The required amount of transversal reinforcement $\left(\rho_{w n}\right)$ can thus be calculated by using Eq. (3) and accounting for $F_{w}=$ $b \cdot \frac{d}{2 \cos (\alpha / 2)} \cdot f_{y w n} \cdot \rho_{w n}$, leading to:

$\rho_{w n}=(1-\xi) \frac{8 \rho}{3} \frac{f_{y}}{f_{y w n}} \cos ^{2}(\alpha / 2)$

where the value of coefficient $\xi$ (which define the amount of total force transferred by the first model, Fig. 9b) depends mostly on the detailing (development conditions) of the reinforcement and on the cracking state of the nodal region. For low levels of cracking or anchorage forces, first model (Fig. 9b) becomes prevalent, whereas the second model (Fig. 9c) becomes more active as extensive cracking of larger chord forces develop. According to the experimental and numerical (EPSF) investigations, this depends mainly on:

- The value of the angle $\alpha$, influencing both the distance of the inclined compression strut (Fig. 9b) to the tensile (cracked) region and the angle between the struts and the ties

- The amount of mechanical flexural reinforcement ratio $\left(\rho \cdot f_{y} / f_{c p}\right)$, determining the total amount of force to be deviated in the nodal region

According to the design philosophy [40,41] of Model Code 2010 [38], a Levels-of-Approximation approach could be used for estimate of parameter $\xi$. For preliminary design purposes (Level-ofApproximation I) and a simple and safe estimate, coefficient $\xi$ can be set as $\xi=0$ (chord forces fully deviated by the transversal reinforcement). For more refined analyses (higher order Levelsof-Approximation), calculation of coefficient $\xi$ can be performed through EPSF analyses as a function of the angle $\alpha$ and the mechanical reinforcement ratio $\rho \cdot f_{y} / f_{c p}$.

A parametric study has been performed by the authors for values of $\alpha$ between $90^{\circ}$ and $140^{\circ}$ and for values of $\rho \cdot f_{y} / f_{c p}$ up to 0.3 . To do so, the minimum required amount of transversal reinforcement leading to failure by yielding of the flexural reinforcement $\left(M_{R} / M_{\text {flex }}=1\right)$ is searched. The geometry selected for the EPSF analyses is shown in Fig. 10a (accounting for inclined transversal reinforcement in the nodal region). The results are shown in Fig. 10b for the EPSF calculations (dotted line) as well as an approximation of the results by means of the following expression (solid line, fitted on the basis of an analysis of governing parameters, Fig. 10):

$\xi=0.4 \cdot \cos \left(\frac{\alpha}{2}\right)+\frac{0.02 \cdot f_{c p}}{\rho \cdot f_{y}} \leqslant 1.0$

This formula is to be applied for values of $\alpha \geqslant 90^{\circ}$. By using Eq. (3) in combination with Eq. (5) the required amount of transversal reinforcement $\rho_{w n} \cdot f_{y w n} / f_{c p}$ can thus be determined, see Fig. 10c and 
d. On that basis, all final checks (size of struts, anchorage detailing) can be easily performed for the selected geometry (refer to rigidplastic stress field [29] of Fig. 9e).

\section{Conclusions}

This paper summarises the results of an experimental and theoretical investigation on the behaviour of corners of RC frame structures subjected to opening bending moments. Its main conclusions are:

1. Opening corners may potentially present poor performance and a rather brittle behaviour at failure. The behaviour and strength of such members is highly influenced by the reinforcement layout, angle of the corner, flexural reinforcement ratio and transversal reinforcement ratio.

2. Best mechanical performances are obtained for hooked flexural reinforcement anchorage. On the contrary, flexural bent bars anchored in the compression chords outside the nodal region lead to poor performances.

3. Providing secondary (transversal) reinforcement, improves significantly the nodal regions performances both in terms of strength and deformation capacity. A minimum value of the transversal reinforcement (leading to failures by yielding of the flexural reinforcement) can be identified in these regions.

4. Design of such members can be consistently performed based on lower-bound solutions of the theory of plasticity such as Elastic-Plastic Stress Fields (EPSF), strut-and-tie models (STM) or rigid-plastic stress fields. Guidelines are provided based on a number of numerical analyses (EPSF) and analytical formulas (based on equilibrium models as STM).

\section{References}

[1] Schlaich J, Schäfer K, Jennewein M. Toward a consistent design of structural concrete. PCI J 1987;32(3):75-150.

[2] Foster J, Gilbert RI. The design of nonflexural members with normal and highstrength concretes. ACI Struct J 1996;93(1):3-10.

[3] Abdul-Wahab HMS, Ali WM. Strength and behavior of reinforced concrete obtuse corners under opening bending moments. ACI Struct J 1989;86(6):679-85.

[4] Abdul-Wahab HMS, Al-Roubai AAM. Strength and behaviour of steel fibre reinforced concrete corners under opening bending moment. Mag Concr Res 1998;50(4):305-18.

[5] Abdul-Wahab HMS, Salman SAR. Effect of corner angle on efficiency of reinforced concrete joints under opening bending moment. ACI Struct J 1999;96(1):115-21.

[6] Akkermann J. Rotation capacity of reinforced concrete frame corners (Rotationsverhalten von stahlbeton-rahmenecken). PhD thesis, Karlsruhe Institute of Technology, Karlsruhe, Germany; 2000. 346 p. [in German].

[7] Balint PS, Taylor HPJ. Reinforcement detailing of frame corner joints with particular reference to opening corners. Cement and Concrete Association, London, UK; 1972. 16 pp.

[8] Cranston WB. Tests on reinforced concrete frames. Cement and Concrete Association, London, UK; 1965. 38 p.

[9] Jackson N. Design of reinforced concrete opening corners. Struct Eng 1995;73(13):209-13.

[10] Johansson M. Reinforcement detailing in concrete frame corners. ACI Struct J 2001;98(1):105-15.

[11] Kordina K. Research on the reinforcement arrangement of knee joints of stair slabs (Untersuchungen über die bewehrungsführung in geknickten treppenlaufplatten), Institut für Baustoffkunde und Stahlbetonbau, Der Technischen Universität Braunschweig, Braunschweig, Germany; 1976. 17 p. [in German].

[12] Kordina K. Reinforcement layout in corner and frame nodal regions (Bewehrungsführung in ecken und rahmenendknoten), Institut für Baustoffkunde und Stahlbetonbau, Der Technischen Universität Braunschweig, Braunschweig, Germany, January; 1984. 93 p. [in German].

[13] Kordina K, Fuchs G. Research on the application of hooked splices on frame corners (Untersuchungen zur anwendung von hakenförmigen übergreifungsstößen in rahmenecken), Institut für Baustoffkunde und Stahlbetonbau, Der Technischen Universität Braunschweig, Braunschweig, Germany, January; 1970.10 p. [in German].
[14] Kordina K, Wiedemann G. Reinforcement layout in frame corners (Bewehrungsführung in rahmenecken), Institut für Baustoffkunde und Stahlbetonbau, Der Technischen Universität Braunschweig, Braunschweig, Germany; 1978. 31 p. [in German].

[15] Lundgren K. Three-dimensional modelling of bond in reinforced concrete (theoretical model, experiments and applications), division of concrete structures. Chalmers University of Technology, PhD thesis, Publication 99:1, Gothenburg, Sweden; 1999. 50 p.

[16] Luo YH, Durrani AJ, Bai S, Yuan J. Study of reinforcing detail of tension bars in frame corner connections. ACI Struct J 1994;91(4):486-96.

[17] Mayfield B, Kong FK, Bennison A. Strength and stiffness of lightweight concrete corners. ACI J 1972;69(7):420-7.

[18] Mayfield B, Kong FK, Bennison A, Twiston Davies JCD. Corner joint details in structural lightweight concrete. ACI J 1971;68(5):366-72.

[19] Morrow J, Viest IM. Shear strength of reinforced concrete frame members without web reinforcement. ACI J 1957;53(3):833-69.

[20] Nilsson IHE. Reinforced concrete corners and joints subjected to bending moment. The National Swedish Institute for Building Research (Stockholm), Division of Concrete Structures, Chalmers University of Technology, PhD thesis, Document D7:1973, Gothenburg, Sweden; 1973. 249 p.

[21] Noor FA. Ultimate strength and cracking of wall corners. Cement and Concrete Association, London, UK; July 1977. p. 31-5.

[22] Östlund L. The influence of bending radius and concrete cover for deformed bars on the risk of splitting failure in RC structures (Inverkan av bockningsradier and täckande betongskikt hos kamstål på spjälkningsrisken för armerade betongkonstruktioner). The Royal Institute of Technology, Stockholm, Sweden; 1963. [in Swedish].

[23] Skettrup E, Strabo J, Andersen NH, Brondum-Nielsen T. Concrete frame corners. ACI Struct J 1984;81(6):587-93.

[24] Stucki D, Thürlimann B. Testing on frame corners of reinforced concrete (Versuche an eckverbindungen aus stahlbeton), Institut für Baustatik und Konstruktion, ETHZ, Bericht Nr. 8701-1, Zurich, Switzerland; 1990. 68 p. [in German].

[25] Swann RA. Flexural strength of corners of reinforced concrete portal frames. Cement and Concrete Association, London, UK; 1969. 14 p.

[26] van Dijk HA, Nelissen LJM, van Stekelenburg PJ. Behaviour of column-beam connections in reinforced concrete (Het gedrag van kolom-balkverbindingen in gewapend beton), Stevin Laboratory, Department of Civil Engineering, Delft University of Technology, Delft, Netherlands; 1976. 81 p. [in Dutch].

[27] Wästlund G. Reinforcement of RC corners (Om armering av vinkelformade betongkonstruktioner). Betong, No. 1, Stockholm, Sweden; 1935. p. 22-35. [in Swedish].

[28] Leonhardt F, Mönnig E. Lectures on structural concrete, part three, principles for reinforcing steel in concrete (Vorlesungen über Massivbau, Dritter Teil, Grundlagen zum Bewehren im Stahlbetonbau), Springer-Verlag, Berlin, Germany; 1974. 244 p. [in German].

[29] Muttoni A, Schwartz J, Thürlimann B. Design of concrete structures with stress fields. Basel, Switzerland: Birkhäuser Verlag; 1996. 143 p.

[30] Fernández Ruiz M, Muttoni A. On development of suitable stress fields for structural concrete. ACI Struct J 2007;104(4):495-502.

[31] Kostic N. Stress fields topology for design of structural concrete (Topologie des champs de contraintes pour le dimensionnement des structures en béton armé), PhD thesis, No. 4414, EPFL, Lausanne, Switzerland; 2009. 235 p. [in French].

[32] Hegger J, Sherif A, Roeser W. Nonlinear finite element analysis of reinforced concrete beam-column connections. ACI Struct J 2004;101(5):604-14.

[33] Johansson M. Structural behaviour in concrete frame corners if civil defence shelters (non-linear finite element analyses and experiments). Department of Structural Engineering, Chalmers University of Technology, PhD thesis, Publication 00:2, Gothenburg, Sweden; 2000. 242 pp.

[34] Johansson M. Nonlinear finite-element analyses of concrete frame corners. J Struct Eng 2000;126(2):190-9.

[35] Angelakos B. The behavior of reinforced concrete knee joints under earthquake loads. PhD thesis, Department of Civil Engineering, University of Toronto, Toronto, Canada; 1999. 316 p.

[36] Cote PA, Wallace JW. A study of reinforced concrete knee joints subjected to lateral cyclic loading. College of Engineering, Clarkson University, Report No. CU/CEE-94-04, Potsdam, USA; 1994. 143 p.

[37] McConnell SW, Wallace JW. Behavior of reinforced concrete beam-column knee-joints subjected to reversed cyclic loading. Department of Civil and Environmental Engineering, Clarkson University, Report No. CU/CEE-95-07, Potsdam, USA; 1995. 197 p.

[38] FIB, fib Model Code 2010. Final draft, fib, Lausanne, Switzerland; September 2011. 653 p.

[39] Campana S, Muttoni A. Analysis and design of an innovative solution for tunnels using elastic-plastic stress fields. In: Proceeding of the 8th fib-PhD symposium. Copenhagen, Denmark; 2010. p. 75-80.

[40] Muttoni A, Fernández Ruiz M. The levels-of-approximation approach in MC 2010: application to punching shear provisions. Struct Concr 2012;13(1):32-41.

[41] Muttoni A, Fernández Ruiz M. Levels-of-approximation approach in codes of practice. Struct Eng Int 2012;2(2):190-4. 